\title{
THE ANALYSIS OF THE CHARACTERISTICS OF SWIRL CHAMBER FOR COOLING HOT WATER
}

\author{
Sergey V. Goldaev ${ }^{1}$, Kseniya B. Tretyakova ${ }^{1, *}$ \\ ${ }^{1}$ National Research Tomsk Polytechnic University, 634050 Tomsk, Russia
}

\begin{abstract}
The alternative way of cooling water circulating in the swirl chamber (SC) was considered. The method for calculating SC was improved and automated. The analysis of the main characteristics of the $\mathrm{SC}$ was performed.
\end{abstract}

\section{Introduction}

In many industries there is a problem of cooling the circulating water to the desired temperature. Artificial ponds, as well as cooling towers, are used as coolers. While operating the cooling towers there is an uneven water distribution in the cross section; liquid carryover and hazardous substances from the cooling towers, that lead to a negative impact on the environment; freezing of the elements of the cooling towers and breakdown take place in winter. The application of swirl chamber (SC) with a spray device was proposed in order to improve the efficiency of the cooling process of circulating water in industrial plants, [1].

\section{Description of the swirl chamber}

Hot water flows to SC (fig. 1) through the nozzle 1, gets to the spray gun 2, mounted on the shaft, where it is distributed to disks with different diameters.

\footnotetext{
*Corresponding author: tretyakova-kseniya@mail.ru
} 


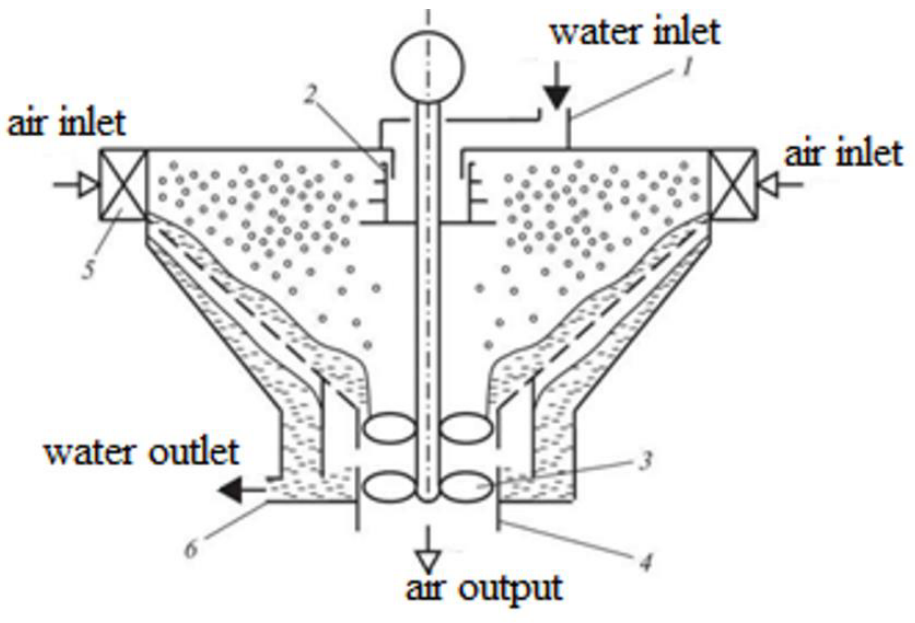

Fig. 1. Scheme of SC disk spray gun:

1 - nozzle for hot water inflow; 2 - disk spray gun; 3 - blades; 4 - nozzle for air outflow; 5 - tangentially blade swirler; 6 - nozzle for cooled water outflow.

When the shaft rotates, the liquid come off the disks of the spray as drops, it throws in different directions, forming a wide spray pattern. Rotating at the same angular velocity, the disks create polydisperse drop spray, providing uniform filling of the working area of the machine, eliminating stagnant zones and increasing the efficiency of heat and mass transfer process [1].

The blades 3 are mounted on the shaft. They are located in the nozzle 4 for the air outflow in several rows at a distance from each other, that lets the the working area of VC increase. Rotating on the shaft blades create a low pressure in the nozzle 4, that provides the air draft into the chamber through the tangentially blade swirler 5 . The air gets rotation motion, moving toward the center of the machine, involving the drops. This interaction leads to the formation of the fine rotating drop layer in the working area. The cooled water is derived from the SC through the nozzle 6 [1].

\section{Results and discussion}

The short-cut method, that provides sufficient accuracy of calculation, was developed.

The formula [1] describes the calculation of the temperature of the drops cooling.

As the dimensions of some parameters are unknown, the formula is replaced for the simplified formula, found from the equation of heat transfer between air and water.

$T_{W}=T-\left(T-T_{W 0}\right) e^{-B_{k} \tau}$,

Where $B_{k}=6 \alpha /\left(c_{L} \rho_{L} d_{k}\right), \tau-$ the contact time of the maximum diameter drops and the air, $\mathrm{s}$, at $\tau=0, T_{L}=T_{k 0}$. 


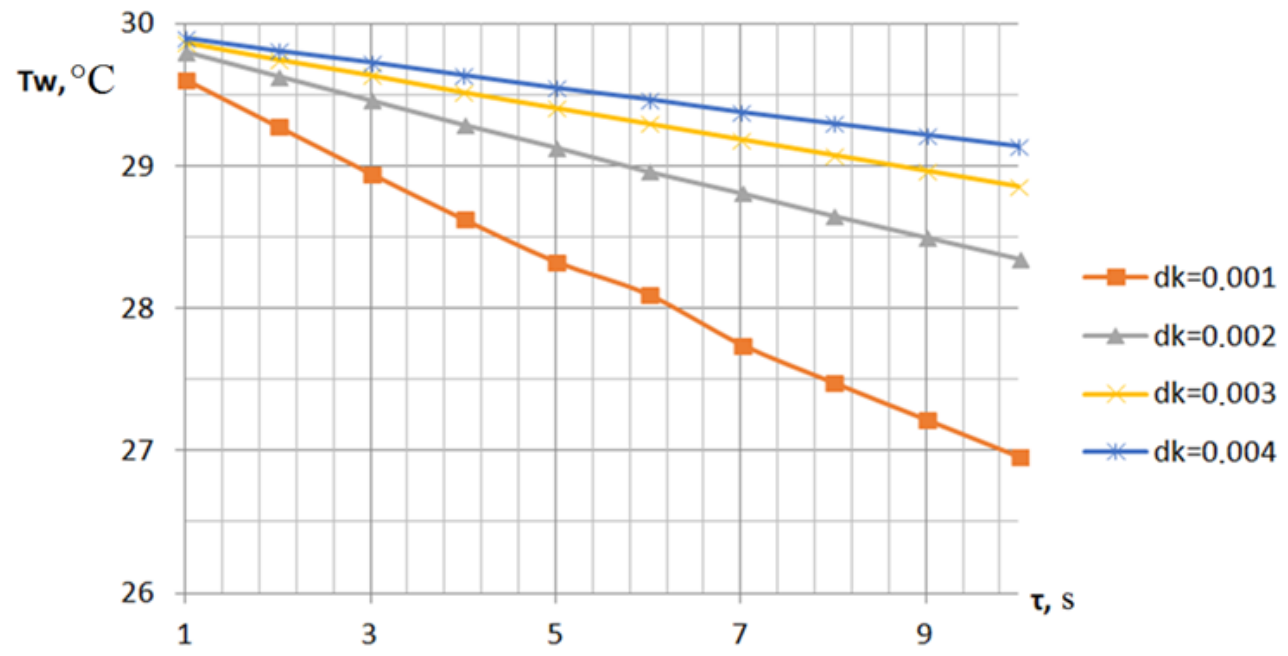

Fig. 2. The dependence of the temperature of the cooling drops and the drop diameter.

Figure 2 shows dependence of the temperature of the cooling drops and the contact time. The graph shows that the smaller the diameter of the drops, the more effective the cooling.

The diameter of the output nozzle $m$ was found by the known values of air mass flow $G_{\mathrm{m}}$ in $\mathrm{kg} / \mathrm{s}$, its density $\rho_{\mathrm{G}}$ at a given temperature, number of drive turns $n$ according to the formula for calculating the axial fan [2]:

$D_{d}=4\left(G_{m} / n \rho_{G}\right)^{1 / 3}$,

In order to obtain the minimum air flow resistance the speed of the air, outflowing from the SC equals the speed at the entrance of the machine, $\mathrm{m} / \mathrm{s}$ :

$W_{\text {en }}=4 G_{m} / \pi D_{d}^{2} \rho_{G}$,

Hydraulic resistance of the device was determined from the expression $\Delta p=\xi_{\mathrm{en}} \frac{\rho_{G} W_{\mathrm{en}}^{2}}{2}$, where $\xi_{\mathrm{en}}=5.5\left(L_{m} / G_{m}\right)^{0.4}$ coefficient of resistance chamber

Useful capacitance of the drive, W:

$D_{d}=4\left(G_{m} / n \rho_{G}\right)^{1 / 3}$,

Figure 3 shows that the flow resistance increases with increasing the flow rate.

The analogue of Glaser for assessing the effectiveness of cooling was introduced to the methodology of the calculation.

$\chi=Q / N$,

Where $Q=\alpha \cdot \Delta T \cdot S_{k}$, heat load, W; $\alpha$ - coefficient of heat transfer from the water to the air, $\mathrm{W} /\left(\mathrm{m}^{2} \mathrm{\kappa}\right) ; \Delta T$ - the difference between the water and air temperatures, $\mathrm{\kappa} ; S_{\mathrm{k}}-$ the drop area, $\mathrm{m}^{2}$ 


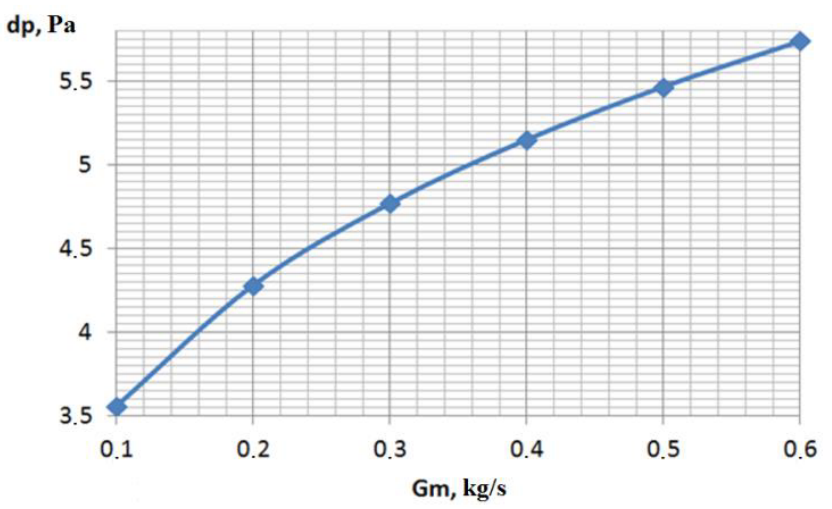

Fig. 3. Dependence of the unit hydraulic resistance from the mass air flow.

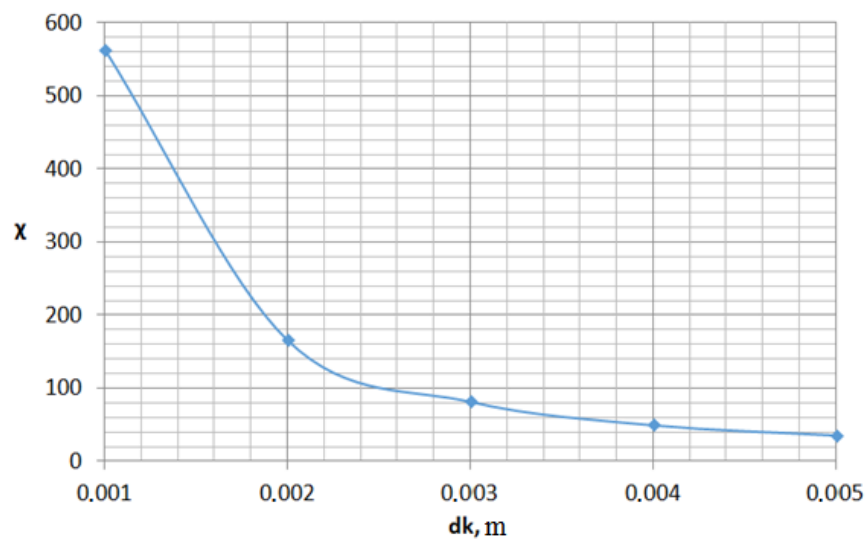

Fig. 4. Dependence of the Glaser criterion analogue from the droplet size.

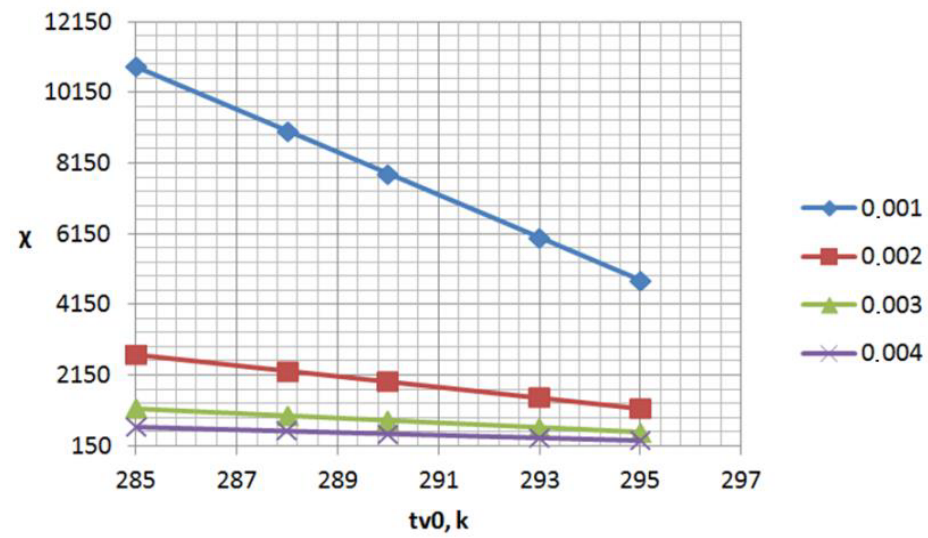

Fig. 5. Dependence of Glaser criterion analogue from the air temperature at the entrance to the block.

Figures $4-6$ show the dependence of the Glaser criterion analogue from the droplet size. Its highest value of 560 was obtained for the drops of $1 \mathrm{~mm}$ diameter. With the increasing of the droplet size the value of this criterion decreases and with the diameter of 2 $\mathrm{mm}$ it equals 160 , with a diameter of $3 \mathrm{~mm}$ - equals 80 . 
The comparative analysis has shown that the spraying cooling towers and cooling towers with regular packing are the most effective, but their disadvantage is in the presence of droplets ablation, minimizing the creation of swirling air flow.

The effectiveness of the cooling water was estimated by the parameter $E_{T}=1-T_{L} / T_{L 0}$, and the proportion of evaporated water was estimated by the parameter $E_{m}=\left(1-L_{m} / L_{m 0}\right) \cdot 100 \%$ [7]

Cooling of water flow rate slows down in the SC with air flow decreasing, as the driving force for heat transfer tends to zero [7].

With the increase in equilibrium moisture content the water evaporation rate decreases with increasing initial air temperature. In addition, increase of the air velocity entering the $\mathrm{SC}$ influences on the reduction of the percentage of water vapor, as the water drops are in the work area less time at the same volume [7].

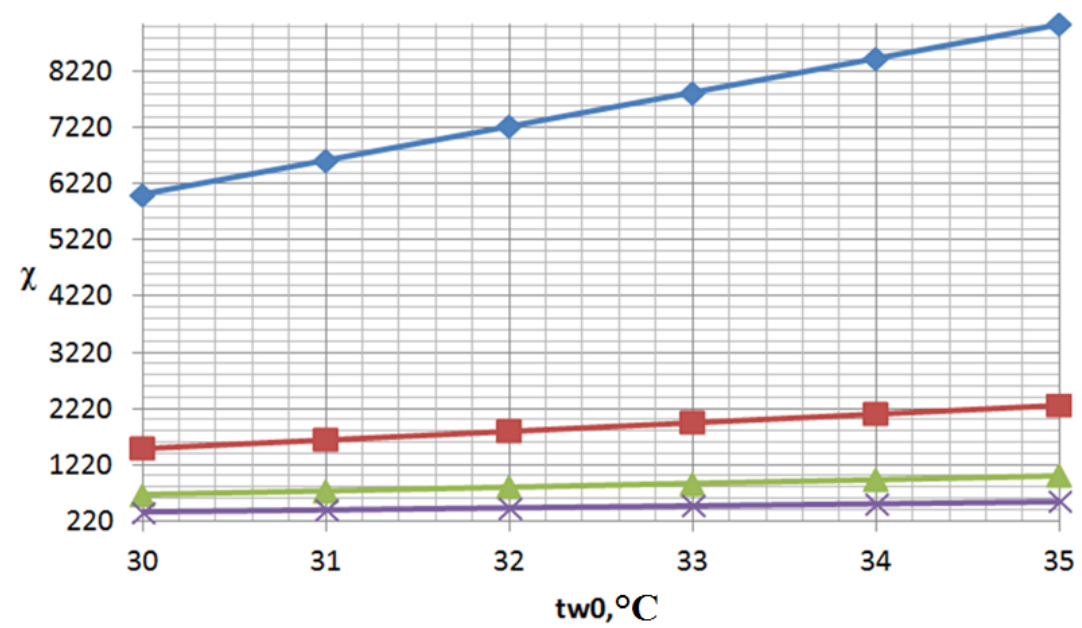

Fig. 6. Dependence of Glaser criterion analogue from the water temperature at the entrance to the block.

\section{Conclusion}

Approximate method for calculating the size of the SC in Turbo Pascal was implemented, the calculation results satisfactorily meet the data of the mathematical modeling [1].

\section{References}

1. A.V. Dmitriev, O.S. Dmitriev, A.N. Nikolaev, Ind. Power 8 (2013)

2. V.M. Cherkassy, pumps, fans, kompressory (Energoatomisdat, Moscow, 1984) [in Russian]

3. D.G. Pazhi, V.S. Galustov, Basic techniques of atomization of liquids (Chemistry, Moscow, 1984) [in Russian]

4. Y.I. Arefiev, N.V. Spiridonov Proceedings of meetings and conferences on hydraulic engineering. Hydro - aerodynamics studies and design of cooling of thermal and nuclear power plants (Energoatomnzdat., Leningrad, 1985) [in Russian]

5. A. H. Lefebvre, Hemisphere Publishing (1989)

6. B.C. Ponomarenko, Chem. Ind. 7 (1996)

7. A.V. Dmitriev, O.S. Makusheva, N.A. Nikolaev, Chem. Pet. Eng. 7 (2011) 